Article

\title{
Exploring the Factors Affecting Mode Choice Intention of Autonomous Vehicle Based on an Extended Theory of Planned Behavior-A Case Study in China
}

\author{
Peng Jing ${ }^{1,2, *}$, Hao Huang ${ }^{1}$, Bin Ran ${ }^{2}$, Fengping Zhan ${ }^{1,2}$ and Yuji Shi ${ }^{1,3}$ \\ 1 School of Automotive and Traffic Engineering, Jiangsu University, Zhenjiang 212013, China; \\ villa.huangh@foxmail.com (H.H.); xiaozhan409@163.com (F.Z.); YUJISHI@ujs.edu.cn (Y.S.) \\ 2 Department of Civil and Environmental Engineering, University of Wisconsin-Madison, \\ 1415 Engineering Drive, Madison, WI 53706, USA; bran@engr.wisc.edu \\ 3 School of Civil Engineering and the Environment, University of Southampton, Highfield, \\ Southampton SO17 1BJ, UK \\ * Correspondence: jingpeng@ujs.edu.cn
}

Received: 17 January 2019; Accepted: 20 February 2019; Published: 21 February 2019

\begin{abstract}
Autonomous vehicle (AV) is an innovative transport option that has the potential to disrupt all industries tied to transportation systems. The advent of AV technology will bring a novel on-demand mobility pattern such as shared autonomous vehicle (SAV). To promote AV technology, it is important to understand which factors influence travelers' intention to use AVs and SAVs. This paper collected literature from databases such as Scopus, Web of Science and ScienceDirect, and made a systematic review. The study aims to explore the determinants that influence travelers' behavioral intentions towards use AVs and SAVs based on an extended version of the theory of planned behavior, which incorporates knowledge and perceived risk. This study was tested empirically using a valid survey sample collected from 906 respondents in China. Structural equation model was conducted to investigate the predictors of intentions to use AVs and SAVs. Results showed that knowledge about AV technology and perceived risk are the two main potential obstacles for travelers to use AVs and SAVs. Attitude significantly affects AVs and SAV choice intentions. Subjective norm is the most critical factor affecting the travelers' intention to use AVs. Perceived behavioral control potentially stymie the travelers' intention to use SAVs. The findings will enhance the understanding of travelers' choice motivation from psychological and service perspectives, and provide data support for governments and companies in improving travel management strategies and product services.
\end{abstract}

Keywords: autonomous vehicle; shared autonomous vehicle; travel mode choice; behavior intention; theory of planned behavior; sustainable transportation

\section{Introduction}

Traffic safety and congestion are major transportation issues in many areas around the world. Driver errors remain the primary cause of vehicle collisions, and the increasing number of private vehicles is worsening traffic congestion. With progress in advanced vehicular technologies, the emergence of AV provides travelers with an alternative, safer and more sustainable transportation mode. AV (also known as driver-less and self-driving) is defined as a motor vehicle capable of sensing its environment and navigating entirely without human driver's active input [1,2]. AV technology has received considerable attention in major car manufacturers and IT companies. Under the background of the sharing economy, the advent of AV technology will bring a novel mobility pattern such as SAV, which 
could transform vehicles from an owned product to an on-demand service [3-5]. SAVs can drive to pick up passengers autonomously without moving to a waiting spot. It can provide a service comparable to that of a taxi without driver, rather than searching for and walking long distances to an available vehicle. Without the need for a driver, acquisition, insurance, travel, and parking costs could be lower than those of personal vehicles. In addition, several variable costs such as depreciation, maintenance and cleaning could also be reduced to a certain extent, and could be shifted to the entity vehicle. One of the largest costs of vehicle ownership is the depreciation cost, the value of the car could be lost over time. Although it will be years before widespread adoption of AV technology, some studies suggested clearly that AV technology will have a devastating impact on traditional transportation systems. On the one hand, AV technology could effectively reduce traffic accident and provide a better solution for road safety, traffic congestion and energy consumption by avoiding unnecessary brake and maintaining the best headway [6-10]. On the other hand, AVs and SAVs could also increase trip number and travel distance by eliminating driving burden and making motorized travel more accessible (to senior citizens and persons with disabilities, for example), which will lead to an increase in the number of AVs or SAVs on the road and the further aggravation of road traffic congestion [11]. In the early stage of AV technology, traffic congestion might not be improved and even worsened due to congestion-inducing effects of shared fleets of AVs and mixed traffic fleet condition [12,13]. In the long term, with the popularity of AV technology and the increase in AV penetration on the road, AVs and SAVs could dramatically reduce congestion caused by human driving behavior and improve the road transportation efficiency $[10,14,15]$. The impact of AV technology on transportation system, especially whether it can alleviate traffic congestion and reduce traffic accidents, depends to a large extent on travelers' mode choice. Understanding travel mode choice is significant since it affects the daily travel efficiency and AV technology industry development prospects. Furthermore, the analysis of travelers' choice is also an important issue for policymakers, who might decide to implement specific interventions to stimulate the diffusion of innovative and sustainable technology. This circumstance requires a more comprehensive understanding of the factors that influence the intentions of travelers to use AVs and SAVs.

Existing research on AV mainly focuses on macro-level analysis, including policy issues [7,16], legislative supervision [17], SAV dispatch optimization $[5,18,19]$ and the impact on traditional transportation system $[5,20,21]$. In the study of user behavior at the micro-level, individuals' travel mode choice behavior in AV and SAV mobility behavior has already become a hot research topic and recently get more attention. However, the travel mode model used in the study of AV choice behavior mainly regards socioeconomic attribute and travel mode attribute as the explanatory variables of the model [19,22-26], while ignoring the intrinsic influence brought by the individual's preference heterogeneity. In recent years, only a few studies have focused on psychological factors such as safety, technology interest, or environmental concern $[13,27,28]$. However, most of these studies only considered attitudinal factors. To our best knowledge, AVs and SAVs use intention behavior has so far not been studied based on a rigorous theoretical background. When attempting to interpret behavior intention, theory-based model provides a more systematic approach to identifying relevant determinants of the specific behavior, and thereby allows a deeper understanding of it. Recent work in choice models has also emphasized the importance of the explicit treatment of psychological factors which affect decision-making [29]. Especially for research that ultimately aims to implement and change behavior, theory-based approach is more effective for formulating and designing specific measures and interventions [30].

One theory that has been more widely adopted by researchers seeking to explain general travel mode choices is the theory of planned behavior (TPB), which was first proposed by Ajzen [31] based on the Theory of Reasoned Action [32]. This theory seeks to capture the highly complicated reality of travel mode choice making in a framework consisting of attitudes, subjective norm, and perceived behavioral control. In addition, two external factors are added to the TPB model namely: knowledge and perceived risk. We intend to develop an extended TPB theoretical framework to explore the 
determinants of travelers' choice intention to use AVs or SAVs and to fill the research gap by examining a broader range of factors that could influence individuals' intentions in China. China is selected as the study area for analysis, as it is the largest developing country with a rather high motorization level and huge automobile market potential $[33,34]$. The understanding of the basic issues related to travel mode choice for AVs and SAVs remains insufficient in China because the existing research mainly focuses on Western countries. The analysis can provide some insights into the factors that may encourage travelers' adoption of AVs or SAVs, and thereby on the design of transportation policies.

The remainder of this paper is organized as follows. Section 2 provides a further review of the literature on AV and SAV mode choice. Section 3 describes the theoretical framework and research hypotheses used in this analysis. Section 4 presents survey questionnaire design and data collection. Data analysis and model result are described in Section 5. Section 6 discusses the key findings from this analysis and potential policy implications. Finally, conclusions and further research area are discussed.

\section{Literature Review}

Although AV technology is not available to the public yet, several literatures have observed and analyzed the potential impact of the emerging AVs or SAVs on travel mode choice, as well as travel behavior shift. Table 1 summarizes some relevant representative studies on AVs or SAVs travel mode choice, in terms of research object description, influence factors summary and research methods. One of the major concerns in studying the travel mode choices behavior is to understand key factors affecting AV or SAV mode choice behavior intention. Early research mainly illustrated how travelers' perceptions along with their demographic factors influencing their intended use of AVs or SAVs. Many factors have been investigated to examine their influence on AV or SAV choice intention, including age, gender, income, education level and so on. These findings indicate that those that are young, well-educated, of moderate-income, and living in an urban environment tend to be positive about using this innovative travel mode [35-37]. Another strand of research that is relevant to our study uses stated-preference (SP) methods to examine travelers' responses to attributes of the travel mode choice alternatives such as travel time, travel cost, etc. Krueger et al. [24] conducted a stated choice experiment in Australian, participants were asked to make mode choices for a reference trip. The alternatives in this experiment include shared and non-shared AVs, as well as the originally chosen mode used in the reference trip. The alternatives were specified by three travel attributes including travel cost, travel time and waiting time. Shared and non-shared automated mobility showed to be perceived as two distinctive modes by the participants. In addition to the above travel attribute variables, walking time, travel time and time to find parking spot were added in Winter et al. [22] to examine free-floating carsharing services and SAVs mode choice based on a stated choice experiment conducted among the Dutch. Furthermore, Levin et al. [26] and LaMondia et al. [25] anticipates the potential effect of AV on transit demand and long-distance travel choices respectively based on a modified four-step planning model. Scheltes et al. [23] and Liu et al. [19] explored the potential AVs and SAVs mode choice through the agent-based simulation experiment. However, the experiment data was limited to assumption or previous travel survey, and AV technology information was not included, so the models built were not accurately calibrated or validated.

In addition, several additional psychological factors also might influence mode choice intention. Haboucha et al. [13] conducted a stated preference questionnaire survey across Israel and North America. On the basis of the socioeconomic attributes and current commuting characteristics, five attitudinal variables are extracted to explore the individuals' intention to own and use AVs. The result shows that enjoy driving, environmental concern, and Pro-AV attitude played a significant role in estimating the travel mode choice decision. Another dimension of travel mode choice behavior explored in the 2016 survey by MD Yap et al. [28] was the impact of AV on the last mile public transport travel in the Netherlands, which incorporated instrumental attributes, socioeconomic variables and attitudinal indicators in a stated choice experiment. More than 20 attitudinal indicators were provided in the survey to measure the intention to use AVs as last mile transport. This study finds that 
attitude regarding trust and sustainability can play an important role in the choice of travelers to use AVs as last mile transport. AVs were further subdivided into automated gasoline vehicle and automated electric vehicle by Shabanpour et al. [27] to estimate respondents' vehicle choice behavior. Several opinion-based variables related to AVs were included in a stated preference survey in Chicago. This result shows that those who concern safety and environment were more willing to purchase these types of vehicles. Three latent attitudes were organized in a stated preference survey by Nazari et al. [38] to study Washington travelers' insight into shared and private mobility. Results indicate that green travel pattern and mobility-on-demand savviness promote interest in SAVs, whereas safety concern hinders public choice intention of SAVs. From the discussion, much of the previous work on AVs and SAVs has focused on the descriptive, univariate analysis of demographics and travel attribute solely of users based on survey data samples. This paper aims to build on the existing body of literature by examining a statistical sample containing psychological latent variables. In doing so, this study provides an analysis of the travel mode choice intention differences in demographics and psychological latent variables.

Table 1. Summary of the relevant studies on the real-time traffic management problem.

\begin{tabular}{|c|c|c|c|c|}
\hline Author & Country/Area & Research Object & Influence Factors & Method \\
\hline $\begin{array}{l}\text { Nazari et al., } \\
2018 \text { [38] }\end{array}$ & USA & $\begin{array}{c}\text { carsharing, ridesourcing, and } \\
\text { ridesharing with AVs }\end{array}$ & latent variable & SP experiment \\
\hline $\begin{array}{l}\text { Haboucha et al., } \\
2017 \text { [13] }\end{array}$ & $\begin{array}{l}\text { Israel/North } \\
\text { America }\end{array}$ & $\begin{array}{c}\text { current car, private AV } \\
\text { and SAV }\end{array}$ & $\begin{array}{c}\text { demographic variable } \\
\text { travel attribute } \\
\text { latent variable }\end{array}$ & SP experiment \\
\hline $\begin{array}{l}\text { Winter et al., } \\
2017 \text { [22] }\end{array}$ & Netherlands & $\begin{array}{l}\text { free-floating carsharing } \\
\text { services and SAV }\end{array}$ & $\begin{array}{l}\text { demographic variable } \\
\text { travel attribute }\end{array}$ & SP experiment \\
\hline $\begin{array}{l}\text { Liu et al., } 2017 \\
\text { [19] }\end{array}$ & Austin, USA & $\begin{array}{l}\text { human-driven vehicle, SAV, } \\
\text { and transit }\end{array}$ & travel attribute & $\begin{array}{l}\text { Agent-based } \\
\text { simulation }\end{array}$ \\
\hline $\begin{array}{l}\text { Scheltes et al., } \\
2017 \text { [23] }\end{array}$ & Netherlands & $\begin{array}{l}\text { AV, walking/bicycle } \\
\text { and transit }\end{array}$ & travel attribute & $\begin{array}{l}\text { Agent-based } \\
\text { simulation }\end{array}$ \\
\hline $\begin{array}{l}\text { Shabanpour et al., } \\
2017 \text { [27] }\end{array}$ & Chicago, USA & $\begin{array}{l}\text { non-automated gasoline } \\
\text { vehicle, non-automated } \\
\text { electric vehicle, automated } \\
\text { gasoline vehicle, and } \\
\text { automated electric vehicle }\end{array}$ & $\begin{array}{c}\text { demographic variable } \\
\text { travel attribute } \\
\text { opinion-based variable }\end{array}$ & SP experiment \\
\hline $\begin{array}{l}\text { Krueger et al., } \\
2016 \text { [24] }\end{array}$ & Australia & $\begin{array}{l}\text { SAV, SAV without } \\
\text { ride-sharing and public transit }\end{array}$ & $\begin{array}{l}\text { demographic variable } \\
\text { travel attribute }\end{array}$ & SP experiment \\
\hline $\begin{array}{l}\text { MD Yap et al., } \\
2016 \text { [28] }\end{array}$ & Netherlands & $\begin{array}{l}\mathrm{AV}, \text { bus } / \text { tram/metro, } \\
\text { and bike }\end{array}$ & $\begin{array}{c}\text { demographic variable } \\
\text { travel attribute } \\
\text { latent variable }\end{array}$ & SP experiment \\
\hline $\begin{array}{l}\text { LaMondia et al., } \\
\qquad 2016 \text { [25] }\end{array}$ & USA & $\begin{array}{l}\mathrm{AV} \text {, personal vehicle } \\
\text { and air }\end{array}$ & travel attribute & $\begin{array}{c}\text { Four-step } \\
\text { planning model }\end{array}$ \\
\hline $\begin{array}{l}\text { Levin et al., } 2015 \\
\text { [26] }\end{array}$ & USA & $\begin{array}{l}\text { AV with parking or } \\
\text { repositioning, and transit }\end{array}$ & travel attribute & $\begin{array}{c}\text { Four-step } \\
\text { planning model }\end{array}$ \\
\hline
\end{tabular}

\section{Theoretical Framework and Research Hypotheses}

TPB model has achieved a considerable reputation for predicting and explaining human behavior intention [31,32]. According to TPB model, individual's behavioral intentions are explained as a consequence of attitudes, subjective norm and perceived behavioral control. The TPB has been used in a wide range of environmental protection, green behavior, commodity purchases and travel choice behaviors. Most studies have shown that the TPB has good explanatory power for behavioral intentions. This paper attempts to apply TPB to AV and SAV travel mode choice intentions and to explore the key influencing factors. Figure 1 displays the proposed conceptual model hypotheses based on the TPB framework. 


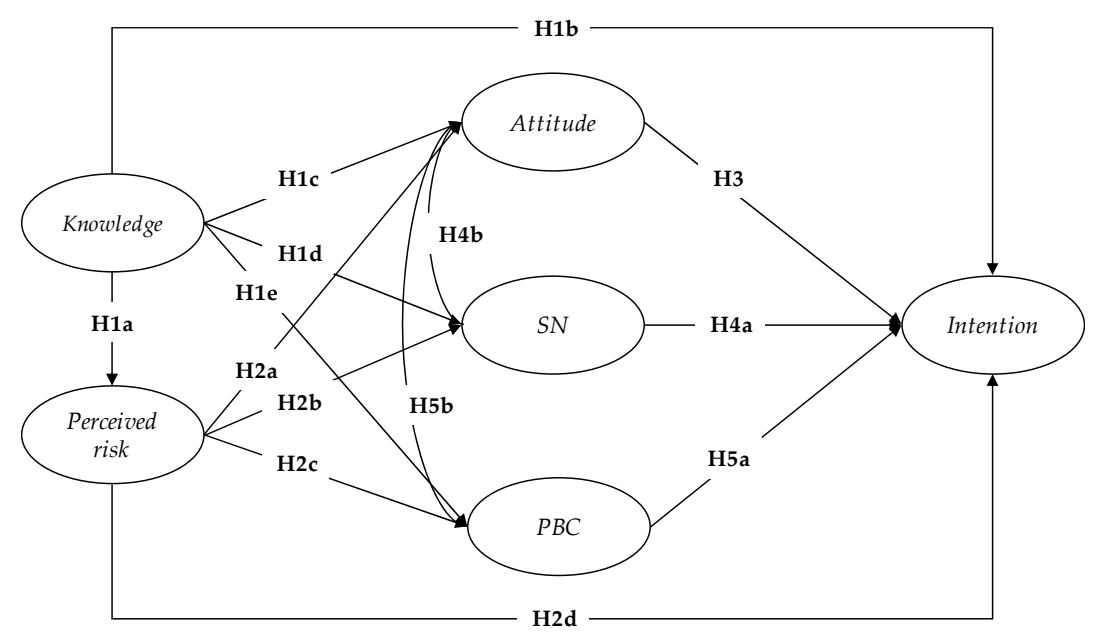

(a) Conceptual research framework based on AV.

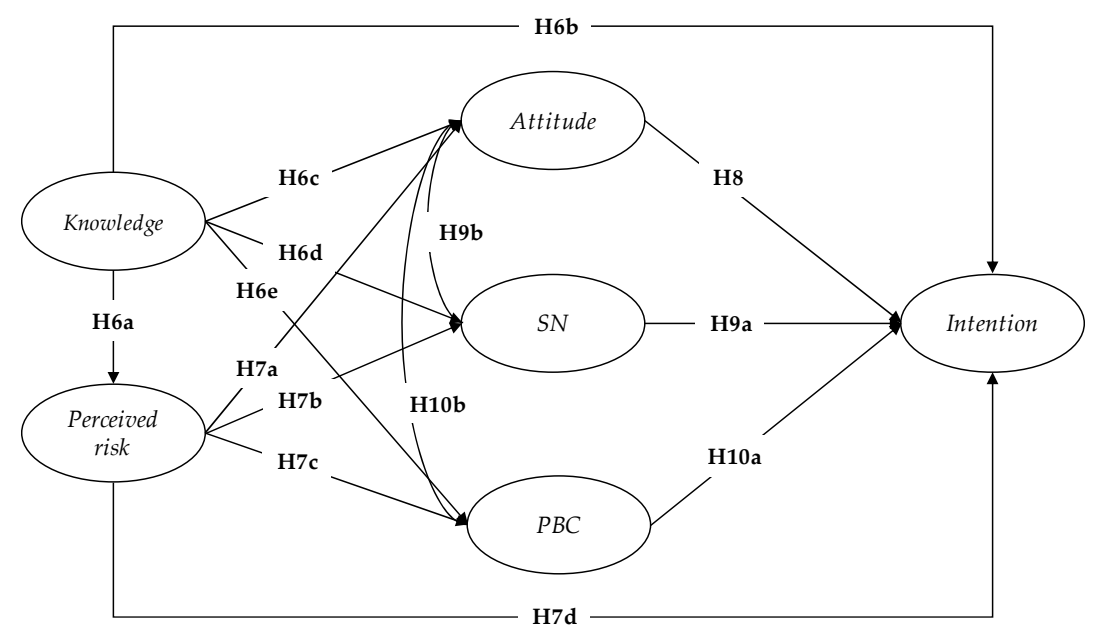

(b) Conceptual research framework based on SAV.

Figure 1. Conceptual research framework.

\subsection{Knowledge about $A V s$ (KN)}

Knowledge is an important construct in behavioral research. It plays a crucial role in individuals' choice decision making [39]. Behavior-related knowledge means knowing how to perform the intended behavior, to determine responsibility for the intended act and to evaluate the perceived effectiveness of the behavioral act [40]. If consumers have a better understanding of the characteristics and attributes of a product, it will not only improve the accuracy of consumers in behavior decision-making, but also reduce the risk of decision-making. A large number of studies have shown that individuals' knowledge of a product plays a crucial role in their attitudes and intentions to choose and use the product [40-42]. Simsekoglu et al. [43] found that the lack of knowledge of e-bikes may be a potential obstacle to residents' use of e-bike in Norway. The research of Barth et al. [44] and Krause et al. [45] have showed that knowledge of electric vehicle can significantly improve the acceptance of electric vehicle, whereas the lack of knowledge can be an obstacle to use electric vehicle. In this study, knowledge will be defined as the product attribute or product knowledge. The product knowledge will include the performance attribute and the advantages of AVs. Based on the above analysis, it can be inferred that travelers' knowledge and experience of AV technology play an important role in regulating and influencing the formation of choice intention. In the context of AV technology, travelers' knowledge of 
$\mathrm{AVs}$ is also important to promote $\mathrm{AV}$ technology development and affect travelers' choice. If a traveler knows less about AV technology, they may have some security concerns when choosing this mode to travel, which means that knowledge about AVs is negatively associated with individuals' perceived risk. Furthermore, if the travelers know more about AV technology, such as the performance attributes of AVs (e.g., operation process, driving comfort, mileage, cost) and the advantages of AVs (such as improving safety and easing traffic congestion), they might be more likely to use AVs with positive attitude and intention. In addition, the lack of knowledge about AVs will further affect the individual's pursuit of important people. Similarly, when travelers know more about the performance attributes and advantages of AVs, they may think that they have the perceived control ability to operate and drive $\mathrm{AVs}$ easily. In contrast, travelers are reluctant to use AVs due to the lack of knowledge and experience in AVs. As a result, the traveler's perceived control on AVs is low, which may prevent the choice behavior of AVs directly. Based on the above viewpoints, this study proposes the following hypotheses:

Hypothesis 1a (H1a): Knowledge about AVs is negatively associated with individuals' perceived risk.

Hypothesis 1b (H1b): Knowledge about $A V$ s is positively associated with individuals' intention to adopt $A V s$.

Hypothesis 1c (H1c): Knowledge about AVs is positively associated with individuals' attitude towards AVs.

Hypothesis 1d (H1d): Knowledge about AVs is positively associated with individuals' subjective norm of AVs.

Hypothesis 1e (H1e): Knowledge about AVs is positively associated with individuals' perceived behavior control to adopt $A V$ s.

\subsection{Perceived Risk (PR)}

Perceived risk refers to the expected negative effects of consumers when they purchase a particular product or service. Perceived risk is a multidimensional variable, including time, function, physical, financial, social and psychological risks [46]. Relevant studies have shown that perceived risk has a negative impact on consumers' attitude and intention to use innovative products or services [47-49]. The risk perception is very crucial as it could affect directly to the purchase and purchasing intention. In the context of $\mathrm{AV}$ technology, these views are equally applicable to the study of $\mathrm{AV}$ choice intention. Perceived risk may be the main barrier for individuals to use AVs and SAVs. In fact, perceived risk is often originated from the lack of knowledge and information about AVs and SAVs. In addition, according to market research reports related to AVs, the potential risks of AV technology are regarded as a key factor affecting the acceptance of AVs. The research of Menon et al. [50] and Zmud et al. [51] show that perceived risk is one of the reasons why the public is unwilling to accept AVs, and the most important one is the potential safety risk of AVs. In the present study, risk perception is defined in terms of the travelers' perceptions of the uncertainty and adverse consequences of using AVs and will be investigated from the view of physical attributes of AVs, financial, and physical (health issue) approach. As an innovative technology product, AVs may have some security and reliability problems [15,52,53], such as the failure of self-driving system (e.g., radar and camera), the paralysis of communication system or hacker attack, which may cause travelers' concerns about safety problems. Therefore, they may have a negative attitude and be unwilling to choose this mode when travelers realize the potential risks of using AVs. In addition, perceived risk has a negative impact on individual's subjective norm and perceived behavior control [54,55]. When travelers realize the potential risks of AVs, they may doubt whether their friends and relatives will support them to use AVs and whether they can learn to use AVs easily. Based on the above viewpoints, this study proposes the following hypotheses:

Hypothesis 2a (H2a): Perceived risk is negatively associated with individuals' attitude towards AVs.

Hypothesis 2b (H2b): Perceived risk is negatively associated with individuals' subjective norm of AVs. 
Hypothesis 2c (H2c): Perceived risk is negatively associated with individuals' perceived behavioral control to AVs.

Hypothesis 2d (H2d): Perceived risk is negatively associated with individuals' intention to AVs.

\subsection{Attitudes toward Behavior (ATT)}

According to the TPB, the main determinant of behavioral intention is attitude. Attitudes toward behavior is a psychological tendency which refers to an individual's favorable or unfavorable evaluations of a particular object or a specific behavior under consideration [31]. A person who believes that positively valued outcomes will result from performing the behavior will have a positive attitude towards such behavior. As a result, attitude can be considered as an important factor in predicting and describing human behavior. On the basis of TPB analytical framework, individual's attitudes are valid predictive variables affecting travel mode choice behavioral intentions [31,56]. Liu et al. [57] pointed out that there was a significant positive impact between travelers' attitudes towards low-carbon travel and choice intention. Stark and Hössingerb [58] found that attitudes have the highest explanatory power for travel-related intention.

Applied to AVs that function as a way to satisfy travelers' need for travel multiformity and convenience. In this study, the behavioral attitude of travelers to AVs reflects the traveler's general evaluation and inclination toward this behavioral intention. The empirical evidence makes it reasonable to assume that if the travelers believe that the AVs would gain a positive outcome associated with the personal aspirations, the more likely would they be to have a favorable attitude toward AVs. Based on the above viewpoints, this study proposes the following hypotheses:

Hypothesis 3 (H3): Individuals' behavioral attitude is positively associated with intention to AVs.

\subsection{Subjective Norm (SN)}

Subjective norm is a social factor that refers to individual's perceived social pressure to engage or not to engage a particular behavior [31]. Subjective norm reflects the influence of salient individuals or groups that have an influence on an individual's behavioral decisions. According to the TPB, subjective norm is a predictor of specific behavior via behavioral intention. However, there are usually not consistent results whether subjective norm was main predictor of travel-related behavior intention. Several studies have shown that subjective norm indeed has a significant and positive influence on behavioral intention, which indicated that pressure from salient individuals or groups motivate or obstruct individuals to perform a specific behavior [59-61]. Subjective norm was found to have the greatest impact on consumers' intention to adopt hybrid electric vehicles in China [61]. The study of Pan et al. [62] found that subjective norms had a positive impact on passengers' travel intention of using low-cost carriers in China. Furthermore, collectivism has a relatively dominant position in many aspects of people's daily life in the context of Chinese rationalizations, thus social pressure may play an important role in influencing people's choice intention [63,64]. In this study, people are not willing to take the lead in choosing this mode with their concerns and wait-and-see attitudes when AVs enter the market in the future. The ideas and practices of the people they matter most in their life may have an important impact on travelers' choice intention. Based on the above viewpoints, this study proposes the following hypotheses:

Hypothesis 4a (H4a): Subjective norm is positively associated with individuals' intention to AVs.

Hypothesis $4 \mathbf{b}$ (H4b): Subjective norm is positively associated with individuals' attitude towards AVs.

\subsection{Perceived Behavioral Control (PBC)}

Perceived behavioral control refers to the perceived ease or difficulty of a particular behavior performance [31]. The more resources and opportunities individuals believe they possess, the fewer 
obstacles they anticipate, and the greater perceived control over the behavior. These resources and opportunities may be divided into internal and external factors, including internal to the individual, such as skills, abilities, knowledge and awareness, or external, such as time, opportunity or the cooperation of other people. Perceived behavioral control has the same ability as actual behavioral control, which will have a direct impact on behavioral intention. Related research have shown that perceived behavioral control is strong determinants of intentions to purchase new energy vehicles $[54,65]$. With regards to AVs, several constraints do exist. Among the most important control factors that influence travelers' behavior intention include knowledge, price/cost, and convenience/availability. On the one hand, people have expressed a certain degree of concerns about AV technology cost [66]. On the other hand, as an innovative technology, accessibility and operation may be more complex than regular vehicle, which makes individuals doubt whether they can access and drive AVs easily. In this study, travelers are more willing to use AVs when they think that the AVs are easier to use and less expensive than private vehicle or taxi under the same conditions. Based on the above viewpoints, this study proposes the following hypotheses:

Hypothesis 5a (H5a): Perceived behavioral control is positively associated with individuals' intention to AVs.

Hypothesis $\mathbf{5 b} \mathbf{( H 5 b ) : ~ P e r c e i v e d ~ b e h a v i o r a l ~ c o n t r o l ~ i s ~ p o s i t i v e l y ~ a s s o c i a t e d ~ w i t h ~ i n d i v i d u a l s ' ~ a t t i t u d e ~}$ towards AVs.

\section{Methods}

Given that AVs and SAVs have not yet made their way into the marketplace, and revealed preference survey data does not offer valuable insights on individuals' mode choice behavior. To study travel mode choice preferences for AVs and SAVs, revealed preference and stated preference were designed to measure individuals' preferences.

\subsection{Survey Design}

The questionnaire was formulated based on the research framework and hypotheses mentioned above. To determine the impact of AVs or SAVs on individual travel mode choice, a stated preference experiment was designed to collect basic data on respondents' response to AVs or SAVs since currently no real AVs or SAVs exist on the market in China. The online survey was conducted through 'SoJump' (https://www.sojump.cn/), a professional online questionnaire survey platform which allows to specify a variety of different question types, store the collected answers and handle the data. The questionnaire survey consisted of two main parts.

In the first part of the survey, the respondents were asked to report their age, gender, income level, education level, driver's license possession, and other demographic information. The second part probed the psychological factors that influenced respondents' travel mode choice decisions. Those latent variable items based on TPB according to the suggestion by Azjen [31] were used to measure their intention to use AVs or SAVs. Each psychological construct was measured by three items on a five-point Likert scale ( $1=$ strongly disagree; $5=$ strongly agree), with 3 serving as neutral [67]. To obtain a better understanding of the respondents' attitudes, 3 or 4 statements were provided for each of the expected latent variables, as presented in Table 2 (Table 2 lists only the measuring items of $\mathrm{AV}$, and those of SAV are similar.). Among the constructs, attitudes consisted of items that aimed to explore the respondents' evaluations of the usefulness of AV. Subjective norm comprised of items that measured the respondents' perceptions of the societal responses to their decision of using adopting AVs (e.g., approval from the most important persons in their lives). Perceived behavioral control contained items that expected to reveal the respondents' perceptions of the ease or difficulty related to adopting AVs (e.g., availability and affordability of AVs in the future); perceived risk comprised of items that aimed to measure the respondents' potential perceived risk regarding AVs. Knowledge contained items that expected to measure the respondents' interpretation of AV technology. Intention 
included items that aimed to measure the respondents' planned behaviors regarding AVs (e.g., use of $\mathrm{AVs}$ in the future instead of regular vehicle).

Furthermore, one of the main obstacles in collecting valid data we encountered was that many respondents did not have enough information about AVs and SAVs to offer a fully formed opinion. Introduction photo and video of AV technology were integrated with the second part to ensure that respondents had an idea of these vehicles.

Table 2. Sources of constructs and items used in the study.

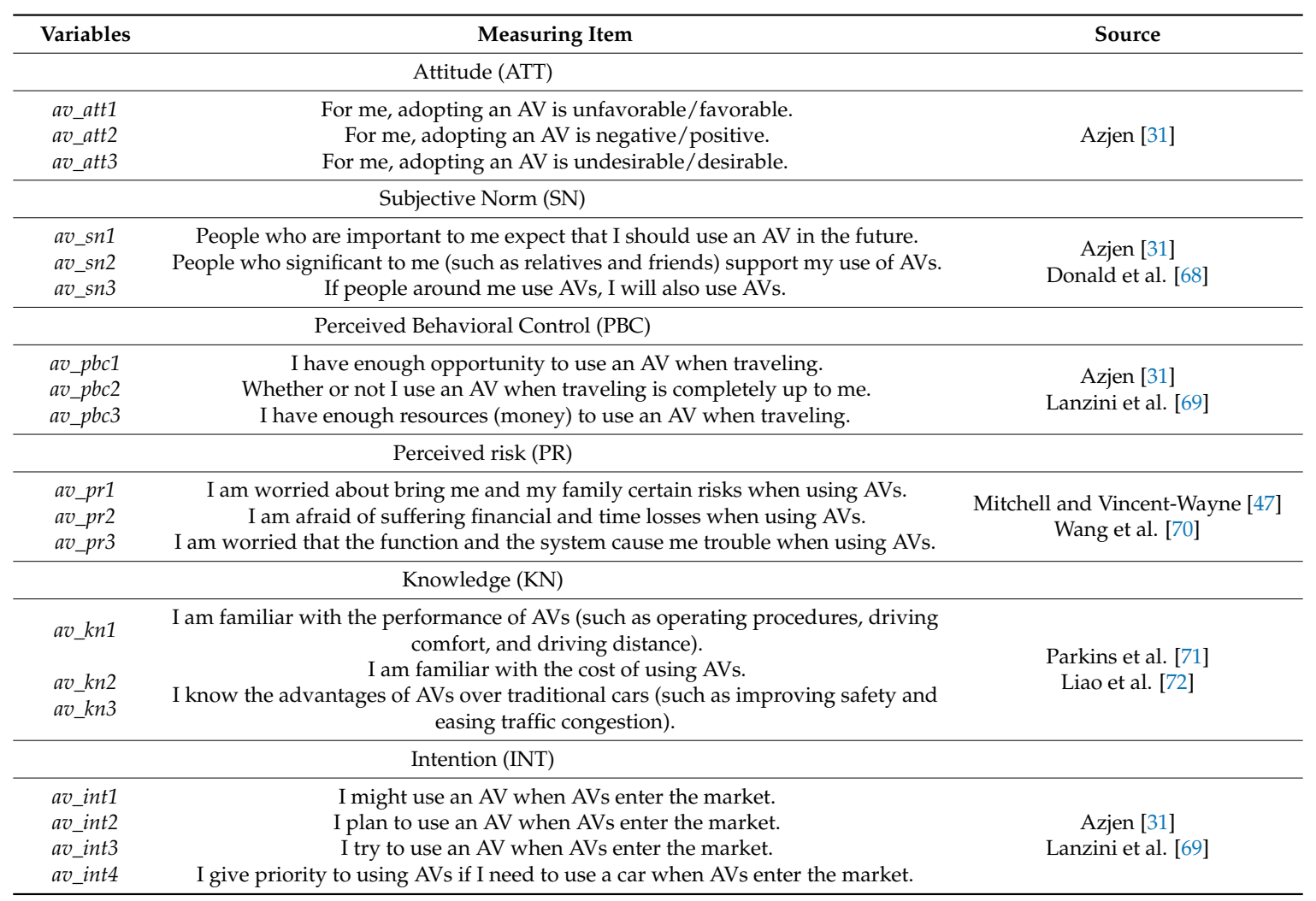

\subsection{Sample and Data Collection}

Two pre-tests were conducted before carrying out the formal questionnaire survey: the first pre-test was a pen and pencil version of the questionnaire which was randomly distributed to 45 college students. According to the comments and feedback, errors in terms of wording, phrasing and sequencing of questions were corrected and the questionnaire was edited online. A second pre-test was conducted by an online survey in order to obtain further feedback on this questionnaire. Data collection was started after correcting the remaining errors and misunderstanding item sources. A total of 1143 questionnaires were collected between 14 January and 5 February 2018, in Zhenjiang, China. 906 valid questionnaires were obtained after eliminating and cleaning the same answers, logical errors and invalid questionnaires. The validity rate of the questionnaires was $79.27 \%$. To prevent repeatedly submitting questionnaires by the same person, the questionnaire submitted by IP address is limited to once.

\section{Analysis and Results}

\subsection{Demographics and Descriptive Findings}

Table 3 summarizes the socio-demographic characteristics of the overall sample participating in this survey. Among the surveyed respondents, $53.75 \%$ were male and $46.25 \%$ were female. The average age was 33.65 years old. The education level was relatively high; more than half of respondents 
had Bachelor's degrees. The majority of personal monthly income was less than 2000 RMB (32.23\%), followed by 2001-4000 RMB (28.70\%), 4001-6000 RMB (20.09\%),6001-8000 RMB (8.50\%), and more than $8000 \mathrm{RMB}(10.48 \%)$. In addition, the majority of respondents did not know much about $\mathrm{AV}$ technology.

Table 3. Summary of respondents' demographic information $(\mathrm{N}=906)$.

\begin{tabular}{|c|c|c|}
\hline Variables & Frequency & Percentage $(\%)$ \\
\hline \multicolumn{3}{|l|}{ Gender } \\
\hline Male & 487 & $53.75 \%$ \\
\hline Female & 419 & $46.25 \%$ \\
\hline \multicolumn{3}{|l|}{ Age } \\
\hline $18-25$ & 272 & $30.02 \%$ \\
\hline $26-35$ & 261 & $28.81 \%$ \\
\hline $36-45$ & 164 & $18.10 \%$ \\
\hline$>45$ & 209 & $23.07 \%$ \\
\hline \multicolumn{3}{|l|}{ Education } \\
\hline Junior school and below & 58 & $6.40 \%$ \\
\hline High school & 131 & $14.46 \%$ \\
\hline College & 238 & $26.27 \%$ \\
\hline Bachelor & 424 & $46.80 \%$ \\
\hline Master or above & 55 & $6.07 \%$ \\
\hline \multicolumn{3}{|l|}{ Income } \\
\hline$<2000$ & 292 & $32.23 \%$ \\
\hline $2001-4000$ & 260 & $28.70 \%$ \\
\hline $4001-6000$ & 182 & $20.09 \%$ \\
\hline $6001-8000$ & 77 & $8.50 \%$ \\
\hline$>8000$ & 95 & $10.48 \%$ \\
\hline \multicolumn{3}{|l|}{ Awareness of AV technology } \\
\hline Strongly Agree & 91 & $10.04 \%$ \\
\hline Agree & 270 & $29.80 \%$ \\
\hline Undecided & 401 & $44.26 \%$ \\
\hline Disagree & 112 & $12.36 \%$ \\
\hline Strongly Disagree & 32 & $3.54 \%$ \\
\hline
\end{tabular}

\subsection{The Reliability and Validity of the TPB Questionnaire}

IBM SPSS v21.0 and AMOS v21.0 were used to test the models and hypotheses proposed in the study. The fitness of the model should be tested before performing the hypothesis test. Confirmatory factor analysis (CFA) was applied to examine the measurement model's reliability and validity. Cronbach's alpha and Composite reliability (CR) were used to check the internal consistency of the items in each construct. Taking AV model as an example, Table 4 shows that the minimum value of Cronbach's alpha was 0.892 , and all values were higher than the recommended minimum value of 0.70 [73]. Therefore, the data was tested to have a good reliability and stability. The CR values of the 6 latent variables were between 0.893 and 0.939 , which were all above the recommended minimum value of 0.7 [74], indicating a high degree of internal consistency among the latent variables. In addition, convergent validity of the model was tested by the construct's standardized factor loading and the average variance extracted (AVE). The result shows that the standardized factor loadings of the 19 observed variables were between 0.726 and 0.969 , all values were higher than the standard of 0.5 [75], indicating that each observed variable had a high explanatory power for their respective latent variable. The AVE values of all the latent variables were between 0.553 and 0.860 , which were all above the recommended minimum value of 0.5 [74]. Hence, all variations of the observed variables explained by their latent variable were greater than the variations explained by their errors, indicating that the average explanatory power of each item in the construct was evident. In summary, the above results show that the measurement model has a good performance on structural reliability, convergence validity and discriminant validity. Table 5 displays the results of discriminant validity test. All AVE values are greater than the inter-construct correlations, indicating the constructs have 
good convergent and discriminant validity. The measurement model was validated and ready for structural model analysis.

Table 4. The results of statistical analysis and confirmatory factor analysis.

\begin{tabular}{|c|c|c|c|c|c|c|c|}
\hline Construct & Measures & Means & $S D$ & Cronbach' $\alpha^{\prime}$ & $\begin{array}{c}\text { Standardized } \\
\text { Factor Loading }\end{array}$ & CR & AVE \\
\hline \multirow{3}{*}{ ATT } & $a v \_a t t 1$ & 3.82 & 0.791 & \multirow{3}{*}{0.940} & 0.944 & \multirow{3}{*}{0.939} & \multirow{3}{*}{0.836} \\
\hline & $a v \_a t t 2$ & 3.81 & 0.813 & & 0.930 & & \\
\hline & $a v \_a t t 3$ & 3.71 & 0.811 & & 0.867 & & \\
\hline \multirow{3}{*}{$\mathrm{SN}$} & $a v \_s n 1$ & 3.58 & 0.750 & \multirow{3}{*}{0.892} & 0.880 & \multirow{3}{*}{0.893} & \multirow{3}{*}{0.736} \\
\hline & $a v \_s n 2$ & 3.57 & 0.749 & & 0.851 & & \\
\hline & $a v \_s n 3$ & 3.56 & 0.740 & & 0.842 & & \\
\hline \multirow{3}{*}{ PBC } & $a v \_p b c 1$ & 3.65 & 0.732 & \multirow{3}{*}{0.908} & 0.969 & \multirow{3}{*}{0.916} & \multirow{3}{*}{0.786} \\
\hline & $a v \_p b c 2$ & 3.66 & 0.768 & & 0.726 & & \\
\hline & $a v \_p b c 3$ & 3.62 & 0.732 & & 0.945 & & \\
\hline \multirow{3}{*}{ PR } & av_pr1 & 2.45 & 0.704 & \multirow{3}{*}{0.936} & 0.895 & \multirow{3}{*}{0.936} & \multirow{3}{*}{0.829} \\
\hline & av_pr2 & 2.47 & 0.745 & & 0.912 & & \\
\hline & av_pr3 & 2.48 & 0.745 & & 0.924 & & \\
\hline \multirow{3}{*}{$\mathrm{KN}$} & $a v \_k n 1$ & 3.51 & 0.946 & \multirow{3}{*}{0.928} & 0.920 & \multirow{3}{*}{0.928} & \multirow{3}{*}{0.811} \\
\hline & $a v \_k n 2$ & 3.48 & 0.997 & & 0.863 & & \\
\hline & $a v \_k n 3$ & 3.46 & 1.029 & & 0.918 & & \\
\hline \multirow{4}{*}{ INT } & $a v \_$int1 & 3.61 & 0.779 & \multirow{4}{*}{0.939} & 0.876 & \multirow{4}{*}{0.935} & \multirow{4}{*}{0.782} \\
\hline & $a v \_$int2 & 3.64 & 0.795 & & 0.883 & & \\
\hline & $a v_{i}$ int3 & 3.58 & 0.776 & & 0.883 & & \\
\hline & $a v_{\text {int4 }}$ & 3.57 & 0.749 & & 0.895 & & \\
\hline
\end{tabular}

Table 5. Results of discriminant validity test.

\begin{tabular}{ccccccc}
\hline & ATT & SN & PBC & PR & KN & INT \\
\hline ATT & $\mathbf{0 . 8 3 6}$ & & & & & \\
SN & 0.703 & $\mathbf{0 . 7 3 6}$ & & & & \\
PBC & 0.623 & 0.691 & $\mathbf{0 . 7 8 6}$ & & & \\
PR & -0.554 & -0.598 & -0.538 & $\mathbf{0 . 8 2 9}$ & & \\
KN & 0.278 & 0.254 & 0.222 & -0.235 & $\mathbf{0 . 8 1 1}$ & \\
INT & 0.692 & 0.712 & 0.727 & -0.669 & 0.296 & $\mathbf{0 . 7 8 2}$ \\
\hline
\end{tabular}

Note: Values along diagonal (in bold) are AVEs of the constructs. Values below diagonal are the correlations between two constructs. ATT: Attitude; SN: Subjective norm; PBC: Perceived Behavioral Control; PR: Perceived Risk; KN: Knowledge; INT: Intention.

\subsection{Structural Model and Hypothesis Tests}

The structural equation model was employed to explore the interrelations among constructs and the model fitting situation is often evaluated by sample size independent fit indices such as chi-square/degree of freedom ( $\left.\chi^{2} / \mathrm{df}\right)$, the comparative fit index (CFI), the Tucker-Lewis index (TLI), the root mean squared error of approximation (RMSEA) and Standardized Root Mean Square Residual (SRMR). According to the rule of thumb, the $\chi^{2} / \mathrm{df}$ value is between 1 and 3 (this value can be between 1 and 5 if the sample size is more than 500), CFI and TLI values are greater than 0.90, RMSEA and SRMR values are smaller than 0.08 , the overall model was regarded as acceptable and excellent. Taking AV model as an example, the related model fit indices of the model in this research was excellent $\left(\chi^{2} / \mathrm{df}=3.719 ; \mathrm{CFI}=0.978 ; \mathrm{TLI}=0.970 ; \mathrm{RMSEA}=0.055 ; \mathrm{SRMR}=0.068\right)$.

Figure 2 presents the path coefficients and the hypothesis testing results of the proposed model with significant paths as solid lines and non-significant paths as dotted lines among variables. The supporting condition of the hypothesis is that the absolute $z$-value should be above 1.96 that is, $p<0.05$. Specifically, it was found that knowledge about AVs showed a positive effect on attitude, subjective norm, perceived behavior control and intention to use AVs, which supported hypothesis H1b, H1c, H1d, and H1e. Knowledge had a negative effect on perceived risk ( $\beta=-0.17, p<0.001$ ), 
which supported hypothesis H1a. However, the knowledge about SAVs had no significant impact on behavioral intention to use SAVs, which was inconsistent with hypothesis H6b. Therefore, knowledge was not significant predictors of behavioral intention in the SAV model. Among the proposed hypotheses related to perceived risk, perceived risk had a significant negative effect on attitude, subjective norm, perceived behavior control and intention to use AVs and SAVs. Thus, those hypotheses H2a, H2b, H2c, H2d, H7a, H7b, H7c, and H7d were supported. Knowledge of AVs and SAVs had a positive effect on perceived risk, which supported H1a and H6a. Furthermore, attitude towards using AVs and SAVs showed a positive effect on behavioral intention to use $(\beta=0.12, p<0.001 ; \beta=0.18$, $p<0.001$ ), which supported H3 and H8. Subjective norm and perceived behavior control were also main significant positive predictors of behavioral intention, which supported $\mathrm{H} 4 \mathrm{a}, \mathrm{H} 5 \mathrm{a}, \mathrm{H} 9 \mathrm{a}$ and $\mathrm{H} 10 \mathrm{a}$ by the data.

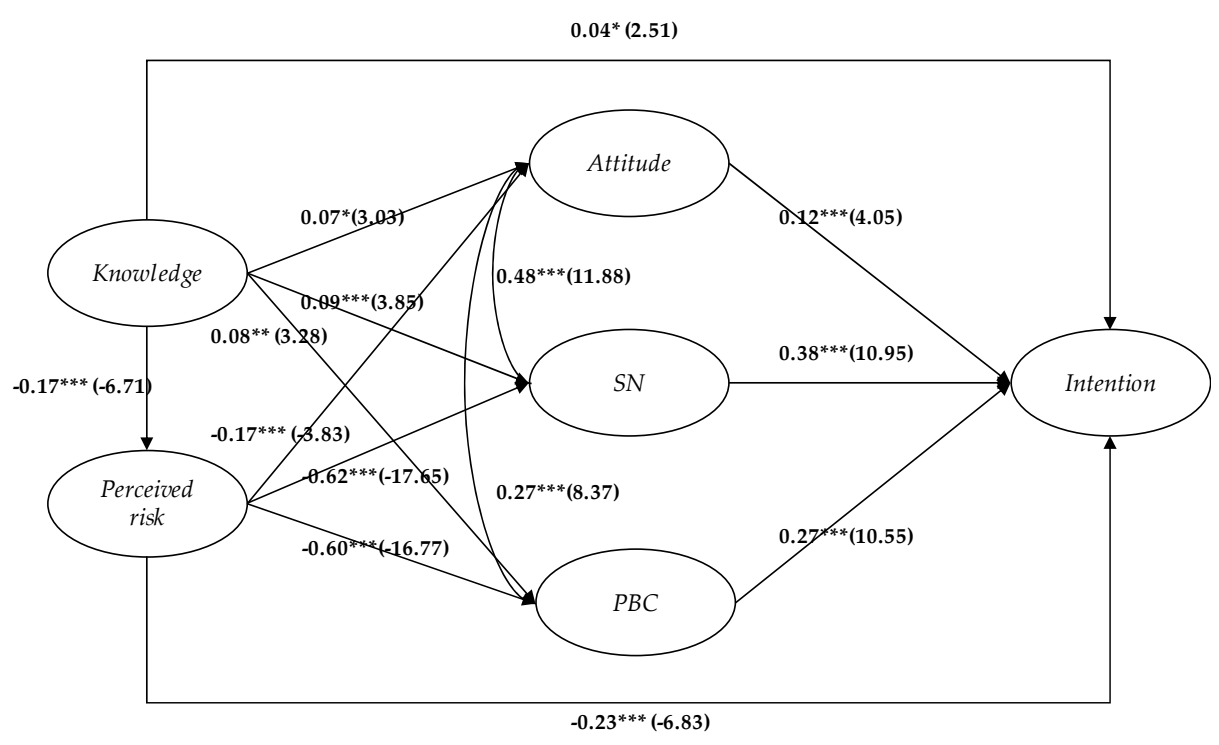

(a) Results of the structural model based on AV.

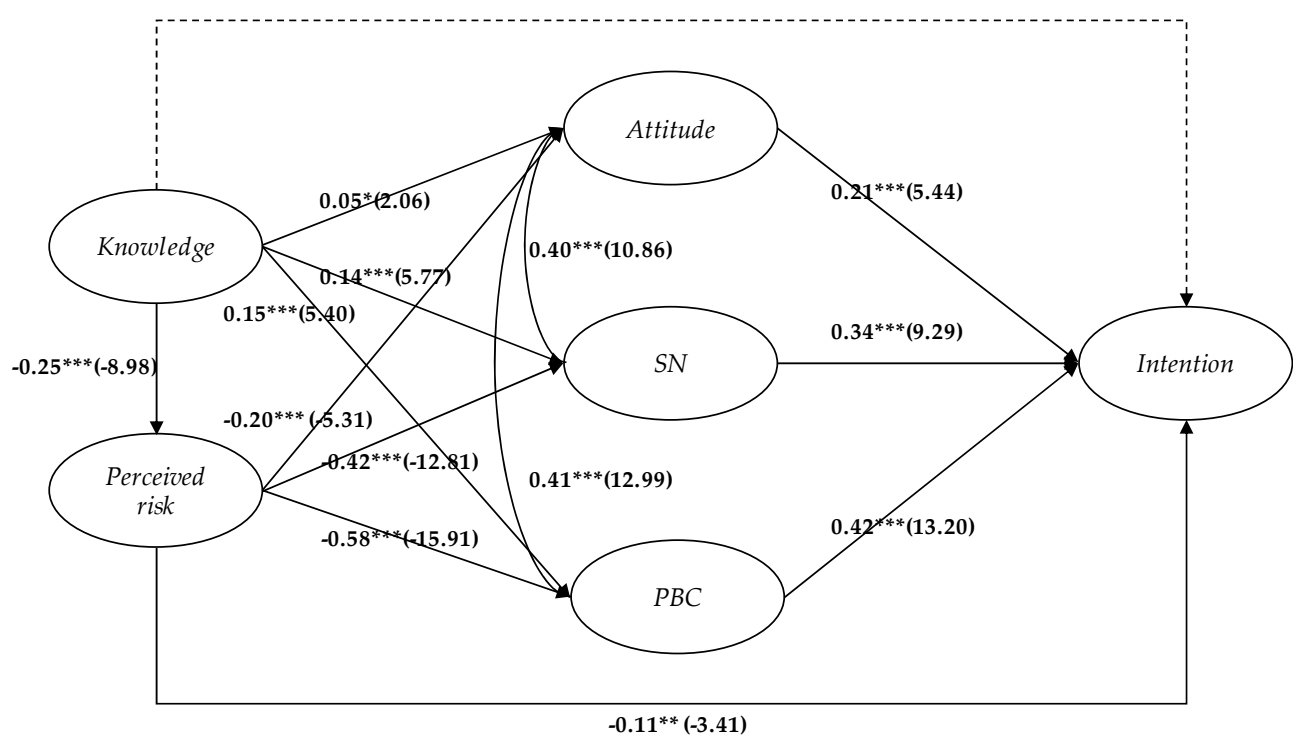

(b) Results of the structural model based on SAV.

Figure 2. Results of the structural model. Note: ${ }^{* * *} p<0.001$; ${ }^{* *} p<0.01 ;{ }^{*} p<0.05$. 


\section{Discussion and Implications}

This study has attempted to understand the travelers' behavior intention to use AVs and SAVs and the key influence factors of behavior intention in the Chinese context. This research established a socio-psychological model to examine AV and SAV choice intentions. Based on the original TPB theoretical framework, this study also attempted to extend the TPB by incorporating two additional psychological variables: knowledge and perceived risk. This paper broadens the TPB application to AV research. The TPB model, despite being extensively used in studies of human behaviors, has only limited use in the AV technology context. The extend TPB models used in this study successfully explained travelers' AV and SAV choice intentions. Overall, the findings suggest that most travelers in China have positive attitudes towards the notion of AVs and SAVs, although they were relatively unfamiliar with specific AV technology. The standard path coefficient in Tables 6 and 7 indicated the degree of correlation between the two variables of this path. Both the TPB components and external factors were assessed for their influence on $\mathrm{AVs}$ and $\mathrm{SAVs}$ choice intentions.

Table 6. Standardized path coefficients and significance level of AV model.

\begin{tabular}{cccccc}
\hline Hypotheses & Path & Standardized Estimate & C.R. & P & Supported $(p<\mathbf{0 . 0 5})$ \\
\hline H1a & PR $\leftarrow$ KN & -0.17 & -6.71 & $* * *$ & Yes \\
H1b & INT $\leftarrow$ KN & 0.04 & 2.51 & 0.012 & Yes \\
H1c & ATT $\leftarrow$ KN & 0.07 & 3.03 & 0.002 & Yes \\
H1d & SN $\leftarrow$ KN & 0.09 & 3.86 & $* * *$ & Yes \\
H1e & PBC $\leftarrow$ KN & 0.08 & 3.28 & 0.001 & Yes \\
H2a & ATT $\leftarrow$ PR & -0.17 & -3.83 & $* * *$ & Yes \\
H2b & SN $\leftarrow$ PR & -0.62 & -17.65 & $* * *$ & Yes \\
H2c & PBC $\leftarrow$ PR & -0.60 & -16.77 & $* * *$ & Yes \\
H2d & INT $\leftarrow$ PR & -0.23 & -6.83 & $* * *$ & Yes \\
H3 & INT $\leftarrow$ ATT & 0.12 & 4.05 & $* * *$ & Yes \\
H4a & INT $\leftarrow$ SN & 0.38 & 10.95 & $* * *$ & Yes \\
H4b & ATT $\leftarrow$ SN & 0.48 & 11.88 & $* * * *$ & Yes \\
H5a & INT $\leftarrow$ PBC & 0.27 & 8.37 & $* * * *$ & Yes \\
H5b & ATT $\leftarrow$ PBC & 0.27 & & & Yes \\
\hline
\end{tabular}

Table 7. Standardized path coefficients and significance level of SAV model.

\begin{tabular}{|c|c|c|c|c|c|}
\hline Hypotheses & Path & Standardized Estimate & C.R. & $\mathbf{P}$ & Supported $(p<0.05)$ \\
\hline H6a & $\mathrm{PR} \leftarrow \mathrm{KN}$ & -0.25 & -8.98 & $* * *$ & Yes \\
\hline $\mathrm{H} 6 \mathrm{~b}$ & $\mathrm{INT} \leftarrow \mathrm{KN}$ & 0.03 & 1.34 & 0.179 & No \\
\hline $\mathrm{H} 6 \mathrm{c}$ & $\mathrm{ATT} \leftarrow \mathrm{KN}$ & 0.05 & 2.06 & 0.040 & Yes \\
\hline H6d & $\mathrm{SN} \leftarrow \mathrm{KN}$ & 0.14 & 5.77 & $* * *$ & Yes \\
\hline H6e & $\mathrm{PBC} \leftarrow \mathrm{KN}$ & 0.15 & 5.40 & $* * *$ & Yes \\
\hline $\mathrm{H} 7 \mathrm{a}$ & $\mathrm{ATT} \leftarrow \mathrm{PR}$ & -0.20 & -5.31 & $* * *$ & Yes \\
\hline $\mathrm{H} 7 \mathrm{~b}$ & $\mathrm{SN} \leftarrow \mathrm{PR}$ & -0.42 & -12.81 & $* * *$ & Yes \\
\hline $\mathrm{H} 7 \mathrm{c}$ & $\mathrm{PBC} \leftarrow \mathrm{PR}$ & -0.58 & -15.91 & $* * *$ & Yes \\
\hline $\mathrm{H} 7 \mathrm{~d}$ & $\mathrm{INT} \leftarrow \mathrm{PR}$ & -0.11 & -3.41 & $* * *$ & Yes \\
\hline $\mathrm{H} 8$ & $\mathrm{INT} \leftarrow \mathrm{ATT}$ & 0.21 & 5.44 & $* * *$ & Yes \\
\hline $\mathrm{H} 9 \mathrm{a}$ & $\mathrm{INT} \leftarrow \mathrm{SN}$ & 0.34 & 9.29 & $* * *$ & Yes \\
\hline $\mathrm{H} 9 \mathrm{~b}$ & $\mathrm{ATT} \leftarrow \mathrm{SN}$ & 0.40 & 10.86 & $* * *$ & Yes \\
\hline $\mathrm{H} 10 \mathrm{a}$ & $\mathrm{INT} \leftarrow \mathrm{PBC}$ & 0.42 & 13.20 & $* * *$ & Yes \\
\hline $\mathrm{H} 10 \mathrm{~b}$ & $\mathrm{ATT} \leftarrow \mathrm{PBC}$ & 0.41 & 12.99 & $* * *$ & Yes \\
\hline
\end{tabular}

\subsection{Perceived Risk, Knowledge and Their Implications}

Perceived risk is conceptualized in various studies according to different study background. In behavior-relative research, perceived risk is mainly associated with a distinct product or product attribute. Three items about perceived risk had higher standardized factors in the confirmatory factor 
analysis (see Table 4). In the extended TPB model, it was observed that perceived risk has a significant relationship with behavioral intention to use $\operatorname{AVs}(\beta=-0.23, \mathrm{z}=-6.83$ at significant level $p<0.001)$ and intention to use SAVs $(\beta=-0.11, \mathrm{z}=-3.41$ at significant level $p<0.001)$. The beta coefficient value of perceived risk is negative, which implies that risk results in a negative impact on behavioral intention. In terms of knowledge, the result shows that knowledge about AV have a statistical relationship with intention to use $\mathrm{AVs}(\beta=0.04, \mathrm{z}=2.51$ at significant level $p<0.05)$. In the AV structure equation model, knowledge about AV not only have an impact on travelers' behavioral intentions directly, but also have an influence on behavioral intentions through attitudes, subjective norm and perceived behavioral control indirectly. It should be noted that knowledge has no significant impact on behavioral intention in the SAV model ( $\beta=0.03, \mathrm{z}=1.34$ at significant level $p>0.05)$, which is consistent with previous research [76]. It is suggested that knowledge related to specific behaviors may be not enough to make decisions in some behavioral studies, and the variables such as potential attitudes and beliefs related to behaviors may be more important than knowledge.

Specifically, travelers' lack of knowledge and potential perceived risks associated with using $\mathrm{AVs}$ and SAVs often lead to travelers produce negative attitudes and further prevent them from traveling by this mode. Therefore, in order to further encourage travelers to use AVs and SAVs in China, special attention should be paid to raising the knowledge about AV technology and reducing the potential perceived risks. Individuals' awareness of AV technology can be improved by advertising the benefits of using AVs and SAVs through both online and offline media campaigns. Additionally, $\mathrm{AV}$ companies can also provide users the opportunity directly to experience AVs and SAVs, because such an experience can improve knowledge about AV technology effectively. SAV companies can purchase insurance and provide security for users to reduce perceived risk and to increase perceived trust. Furthermore, it is also necessary for companies to regularly inspect and maintain the vehicles to eliminate the potential safety hazards of vehicles.

\subsection{Attitude and Its Implications}

Several studies have confirmed that attitude was the main predictor of behavior intention in the social as well as travel-relative behavior context $[31,60,62,68]$. Parallel to studies in the field of social science and travel behavior, the present study also shown that attitude is one of main predictors of intention. This study supports that the impact of attitude was highly significant on behavior intention to use AVs $(\beta=0.12, \mathrm{z}=4.05$ at significant level $p<0.001)$ and also on behavior intention to use SAVs $(\beta=0.21, \mathrm{z}=5.44$ at significant level $p<0.001)$.

In the original paradigm of TPB model, attitude is a positive influence on behavioral intentions which shows that travelers rely on their thoughts and feelings. In this study, attitude was determined by beliefs related to the behavior attitude in survey question. In other words, the travelers have that a positive attitude of AVs and SAVs, are more likely to plan to choose this mode. This finding is consistent with prior research; attitude is an efficient predictor of AV and SAV choice intention $[13,27,28]$. Hence, more efforts should be made to enhance traveler's comprehensive evaluation of choice behavior in the future. Improving the acceptance and recognition of AV technology can significantly enhance the travelers' intention to travel by this mode. Therefore, the government should positively take corresponding measures to emphasize the benefits of AV technology on transportation system, and the positive impact on society/environment benefits. In particular, it is necessary to emphasize the benefits individuals choose AVs and SAVs for personal travel convenience, which enhances individual's accept attitude of AVs and SAVs.

\subsection{Subjective Norm and Its Implications}

Several studies have found that subjective norm is the weakest indicator of behavior intention in original TPB framework [31,77], some other studies also confirmed that subjective social pressure is a significant and powerful predictor of intention $[59,60]$. However, three items used to measure subjective norm in this study had very high factor loadings and appeared to be highly internally 
consistent (Cronbach's alpha $=0.892$ for AV model and 0.881 for SAV model). In addition, the present study results also show that subjective norm is the most critical factor affecting the travelers' intention to use $\operatorname{AVs}(\beta=0.38, z=10.95$ at significant level $p<0.001)$. Moreover, the direct effect of subjective norms on intentions to use SAVs reached 0.34 at significant level $p<0.001$. This finding may provide a new understanding of traveler intentions in the emerging AV markets. On the one hand, compared with Western individuals, Chinese people are influenced by traditional collectivism education. Besides, social pressure has an important impact on the individual's intention to act [78-80]. Individuals are more willing to follow people who are important to them. The thoughts or opinions from friends and family around them are important determinants of personal choice intentions. On the other hand, since $\mathrm{AV}$ is an innovative travel mode in the future and travelers' understanding of $\mathrm{AV}$ is limited, the most travelers may be unwilling to take the lead in using AVs. Travelers may seek suggestion or advice from their family and friends about traveling by this mode. Therefore, perceived social pressure may be a highly salient factor in this context. For the government, it is possible to start with the formulation of policies or regulations and to promote the enthusiasm of users with positive advocacy, thus generating the use intention of AVs. For AV companies, free trial driving and test driving should be conducted to make some people have the willingness to use AVs, then using the word-of-mouth effect to publicize and affect more people's willingness to travel by the mode.

\subsection{Perceived Behavior Control and Its Implications}

Perceived behavioral control was defined in this study as assessing their self-perception of eases/difficulties in AV or SAV use intention. The perceived behavioral control has been also criticized as a significant predictor of behavioral intention in TPB model $[54,62,65]$. In the study, three items used to measure perceived behavior control had high factor loadings and appeared highly internal reliability (Cronbach's alpha $=0.908$ for AV model and 0.907 for SAV model). Furthermore, the significant correlation was verified with perceived behavioral control and both behavior intention to use AVs $(\beta=0.27, \mathrm{z}=10.55$ at significant level $p<0.001)$ and behavior intention to use SAVs $(\beta=0.42, \mathrm{z}=13.20$ at significant level $p<0.001$ ).

In this study, it is found that attributes such as cost, convenience, and availability are significant indicators of perceived behavior control. This finding suggests that travelers in China have a need for perceived control over external resources when choosing AVs as a travel mode. A possible explanation for the importance of perceived behavior control in this study may be related to financial and service control, which may be important aspects of perceived control. Therefore, governments and companies need to take appropriate measures to improve the level of perceived behavior control in the future. The government should focus on infrastructure platform construction and preferential policy formulation, such as providing a certain degree of subsidies and tax benefits to individual consumers. SAV companies should pay more attention to the service design and management provided such as configuring rationally the number of vehicles based on user data, optimizing system and mobile APP design to provide the real-time power, mileage fee information, so that travelers can easily access SAV service.

\section{Conclusions and Limitations}

New forms of mobility mode are entering the market, which will have a huge impact on travel mode choice in the future transportation system. This calls for a thorough understanding of travelers' intentions to use AVs and SAVs in China, which has so far received little research attention. In this paper, we carried out an empirical research on the influencing factors of psychological latent variable on AV technology mode choice intention. The main findings are as follows. By incorporating knowledge and perceived risk, this study has proposed and empirically tested an extended TPB model to understand traveler' behavioral intention to use AVs and SAVs. From a theoretical view, this research implies that the TPB model also has good applicability and validity in the context of AV technology. Knowledge and perceived risk provide another more potential important way to explain other factors that influence 
travelers to use innovative technologies with uncertainty. From an empirical view, these research findings suggest that in order to promote $\mathrm{AV}$ technology choice intention, relevant organizations should focus on improving the credibility of AV to reduce the perceived risk. In addition, travelers' understanding of $\mathrm{AV}$ technology will also increase the intention to choose this mode. As a result, car manufacturers and governments can publicize the benefits of AV technology (such as, easing congestion and increasing mobility) to increase travelers' intention of choosing AVs and SAVs. Finally, considering the critical positive effects of SN and PBC on AV and SAV choice intentions separately, the role of SN and PBC should also be emphasized. This means that free trial driving and test driving make some people have the willingness to use AV technology and improving the potential ability of travelers' behavior control, which is useful for facilitating travelers to use AVs and SAVs.

This study can be improved in several aspects concerning its limitations; these require further research efforts. The first limitation is that most respondents did not have actual experience with $\mathrm{AV}$ technology. The behavioral intention discussed in this study is based on the initial intention of the respondents' knowledge about AV technology gained from new media such as the Internet or television. As AVs enter the market, individuals will be more familiar with AV technology, and their behavioral intentions and their antecedents will be changed in the future. Therefore, a longitudinal tracking study is recommended to further clarify the evolution of behavioral intentions after having more interaction with AV technology [81]. This would be an interesting next research topic. The second limitation is that this research investigated only general SAV mode choice behavior intention; research motivation mechanisms on specific SAV (SAV can be classified from different standpoint, such as SAV with ridesharing or non-ridesharing) mode choice behavior or comparing behaviors may obtain more exciting new findings. The third limitation is that the research sample only comprised Zhenjiang (China) survey data. Therefore, future studies can aim at generalizing and comparing our findings to explore choice intentions in cross-province or different countries. The fourth limitation is that online survey method was adopted in this survey, which may lead to limited sampling and respondent availability. These respondents mainly include the elderly and people who reside in remote areas. Moreover, future studies should explore the role of other factors such as trust, safety, reliability, and driving habits. A more complex structural model with a network of interrelationships among factors can be developed to further study the behavioral intentions to use AVs and SAVs in China. Finally, this paper focused on the relationships between predicting factors and traveler intentions, future research could expand the model to explore the potential relationship between intention and actual behavior in the AV technology context in the future.

Author Contributions: Conceptualization: P.J. and B.R.; data processing: H.H. and Y.S.; formal analysis: P.J. and H.H.; methodology: P.J. and F.Z.; writing—original draft: P.J. and H.H.; writing—review and editing: P.J., F.Z. and B.R.

Funding: This study was supported by the National Natural Science Foundation of China (Grant No. 71871107).

Acknowledgments: The authors would gratefully acknowledge the kind support from the National Natural Science Foundation of China. We are grateful to anonymous reviewers whose valuable suggestions have led to a considerable improvement in the organization and presentation of this manuscript.

Conflicts of Interest: The authors declare no conflict of interest.

\section{References}

1. Anderson, J.M.; Kalra, N.; Stanley, K.D.; Sorensen, P.; Samaras, C.; Oluwatola, O. Autonomous Vehicle Technology: A Guide for Policymakers; Rand Corporation: Santa Monica, CA, USA, 2014.

2. Kuo, P.H.; Krishnamurthy, A.; Malmborg, C.J. Design models for unit load storage and retrieval systems using autonomous vehicle technology and resource conserving storage and dwell point policies. Appl. Math. Model. 2007, 31, 2332-2346. [CrossRef]

3. Alam, M.J.; Habib, M.A. Investigation of the Impacts of Shared Autonomous Vehicle Operation in Halifax, Canada Using a Dynamic Traffic Microsimulation Model. Procedia Comput. Sci. 2018, 130, 496-503. [CrossRef] 
4. Menon, N.; Barbour, N.; Zhang, Y.; Pinjari, A.R.; Mannering, F. Shared autonomous vehicles and their potential impacts on household vehicle ownership: An exploratory empirical assessment. Int. J. Sustain. Transp. 2018, 1-12. [CrossRef]

5. Shen, Y.; Zhang, H.; Zhao, J. Integrating shared autonomous vehicle in public transportation system: A supply-side simulation of the first-mile service in Singapore. Transp. Res. Part A Policy Pract. 2018, 113, 125-136. [CrossRef]

6. Kim, S.-W.; Chong, Z.J.; Qin, B.; Shen, X.; Cheng, Z.; Liu, W.; Ang, M.H. Cooperative perception for autonomous vehicle control on the road: Motivation and experimental results. In Proceedings of the 2013 IEEE/RSJ International Conference onIntelligent Robots and Systems (IROS), Tokyo, Japan, 3-7 November 2013; pp. 5059-5066.

7. Fagnant, D.J.; Kockelman, K. Preparing a nation for autonomous vehicles: opportunities, barriers and policy recommendations. Transp. Res. Part A 2015, 77, 167-181. [CrossRef]

8. Kröger, L.; Kuhnimhof, T.; Trommer, S. Does context matter? A comparative study modelling autonomous vehicle impact on travel behaviour for Germany and the USA. Transp. Res. Part A Policy Pract. 2018. [CrossRef]

9. Zhang, W.; Guhathakurta, S.; Fang, J.; Zhang, G. Exploring the impact of shared autonomous vehicles on urban parking demand: An agent-based simulation approach. Sustain. Cities Soc. 2015, 19, 34-45. [CrossRef]

10. Zhang, W.; Guhathakurta, S.; Khalil, E.B. The impact of private autonomous vehicles on vehicle ownership and unoccupied VMT generation. Transp. Res. Part C Emerg. Technol. 2018, 90, 156-165. [CrossRef]

11. Simoni, M.D.; Kockelman, K.M.; Gurumurthy, K.M.; Bischoff, J. Congestion pricing in a world of self-driving vehicles: An analysis of different strategies in alternative future scenarios. Transp. Res. Part C Emerg. Technol. 2019, 98, 167-185. [CrossRef]

12. Bagloee, S.A.; Tavana, M.; Asadi, M.; Oliver, T. Autonomous vehicles: challenges, opportunities, and future implications for transportation policies. J. Mod. Transp. 2016, 24, 284-303. [CrossRef]

13. Haboucha, C.J.; Ishaq, R.; Shiftan, Y. User preferences regarding autonomous vehicles. Transp. Res. Part C Emerg. Technol. 2017, 78, 37-49. [CrossRef]

14. Pakusch, C.; Stevens, G.; Boden, A.; Bossauer, P. Unintended effects of autonomous driving: A study on mobility preferences in the future. Sustainability 2018, 10, 2404. [CrossRef]

15. Brummelen, J.V.; O’Brien, M.; Gruyer, D.; Najjaran, H. Autonomous vehicle perception: The technology of today and tomorrow. Transp. Res. Part C Emerg. Technol. 2018, 89, 384-406. [CrossRef]

16. Bansal, P.; Kockelman, K.M. Forecasting Americans' long-term adoption of connected and autonomous vehicle technologies. Transp. Res. Part A 2017, 95, 49-63. [CrossRef]

17. Sinanian, M.H. Jailbreak!: What Happens When Autonomous Vehicle Owners Hack into Their Own Cars. Soc. Sci. Electron. Publ. 2017, 23, 357. [CrossRef]

18. Fagnant, D.J. Shared autonomous vehicles: Model formulation, sub-problem definitions, implementation details, and anticipated impacts. In Proceedings of the American Control Conference, Chicago, IL, USA, 1-3 July 2015.

19. Liu, J.; Kockelman, K.M.; Boesch, P.M.; Ciari, F. Tracking a system of shared autonomous vehicles across the Austin, Texas network using agent-based simulation. Transportation 2017, 44, 1-18. [CrossRef]

20. Lam, A.Y.S.; Leung, Y.W.; Chu, X. Autonomous vehicle public transportation system. In Proceedings of the International Conference on Connected Vehicles and Expo (ICCVE), Messe Wien, Vienna, Austria, 3-7 November 2014; pp. 571-576.

21. Moreno, A.T.; Michalski, A.; Llorca, C.; Moeckel, R. Shared Autonomous Vehicles Effect on Vehicle-Km Traveled and Average Trip Duration. J. Adv. Transp. 2018. [CrossRef]

22. Winter, K.; Cats, O.; Martens, K.; van Arem, B. A Stated-Choice Experiment on Mode Choice in an Era of Free-Floating Carsharing and Shared Autonomous Vehicles. In Proceedings of the Transportation Research Board 96th Annual Meeting, Washington, DC, USA, 8-12 January 2017.

23. Scheltes, A.; Correia, G.H.D.A. Exploring the use of automated vehicles as last mile connection of train trips through an agent-based simulation model: An application to Delft, Netherlands. Int. J. Transp. Sci. Technol. 2017, 6, 28-41. [CrossRef]

24. Krueger, R.; Rashidi, T.H.; Rose, J.M. Preferences for shared autonomous vehicles. Transp. Res. Part C Emerg. Technol. 2016, 69, 343-355. [CrossRef] 
25. LaMondia, J.J.; Fagnant, D.J.; Qu, H.; Barrett, J.; Kockelman, K. Long-Distance Travel Mode Shifts Due to Automated Vehicles: A Statewide Mode-Shift Simulation Experiment and Travel Survey Analysis. In Proceedings of the Transportation Research Board 95th Annual Meeting, Washington, DC, USA, 10-14 January 2016.

26. Levin, M.W.; Boyles, S.D. Effects of autonomous vehicle ownership on trip, mode, and route choice. Transp. Res. Rec. 2015, 29-38. [CrossRef]

27. Shabanpour, R.; Mousavi, S.N.D.; Golshani, N.; Auld, J.; Mohammadian, A. Consumer preferences of electric and automated vehicles. In Proceedings of the IEEE International Conference on MODELS and Technologies for Intelligent Transportation Systems, Napoli, Italy, 26-28 June 2017; pp. 716-720.

28. Yap, M.D.; Correia, G.; Arem, B.V. Preferences of travellers for using automated vehicles as last mile public transport of multimodal train trips. Transp. Res. Part A Policy Pract. 2016, 94, 1-16. [CrossRef]

29. Benakiva, M.; McFadden, D.; Train, K.; Walker, J.; Bhat, C.; Bierlaire, M.; Bolduc, D.; Boerschsupan, A.; Brownstone, D.; Bunch, D.S. Hybrid Choice Models: Progress and Challenges. Mark. Lett. 2002, 13, 163-175. [CrossRef]

30. Steinmetz, H.; Knappstein, M.; Ajzen, I.; Schmidt, P.; Kabst, R. How effective are behavior change interventions based on the theory of planned behavior? A three-level meta-analysis. Z. Für Psychol. 2016, 224, 216-233. [CrossRef]

31. Icek, A. The theory of planned behavior. Organ. Behav. Hum. Decis. Process. 1991, 50, 179-211.

32. Blair, H.S.; Jon, H.; Paul, R.W. The Theory of Reasoned Action: A Meta-Analysis of Past Research with Recommendations for Modifications and Future Research. J. Consum. Res. 1988, 15, 325-343.

33. Ma, H.; Yang, X.; Shi, Q. Motorization process and management in big cities in China: Take Beijing as an Example. IATSS Res. 2007, 31, 42-47. [CrossRef]

34. Deng, H.; Ma, A.C. Market structure and pricing strategy of China's automobile industry. J. Ind. Econ. 2010, 58, 818-845. [CrossRef]

35. Bansal, P.; Kockelman, K.M. Are we ready to embrace connected and self-driving vehicles? A case study of Texans. Transportation 2018, 45, 1-35. [CrossRef]

36. Bansal, P.; Kockelman, K.M.; Singh, A. Assessing public opinions of and interest in new vehicle technologies: An Austin perspective. Transp. Res. Part C 2016, 67, 1-14. [CrossRef]

37. Kyriakidis, M.; Happee, R.; de Winter, J.C.F. Public opinion on automated driving: Results of an international questionnaire among 5000 respondents. Transp. Res. Part F: Traffic Psychol. Behav. 2015, 32, 127-140. [CrossRef]

38. Nazari, F.; Noruzoliaee, M.; Mohammadian, A.K. Shared versus private mobility: Modeling public interest in autonomous vehicles accounting for latent attitudes. Transp. Res. Part C 2018, 97, 456-477. [CrossRef]

39. Kaplan, S. Beyond rationality: Clarity-based decision making. In Environment, Cognition, and Action: An Integrated Approach; Oxford University Press: New York, NY, USA, 1991; pp. 171-190.

40. Park, C.W.; Mothersbaugh, D.L.; Feick, L. Consumer Knowledge Assessment. J. Consum. Res. 1994, $21,71-82$. [CrossRef]

41. Wei-Yun, Y.E.; Feng, Z.G.; Wei-Bin, W.U. Investigation on consumer's knowledge and practice about nutrition labeling of food in Guangzhou. Mod. Prev. Med. 2010, 37, 1850-1852.

42. Qian, L.; Yin, J. Linking Chinese cultural values and the adoption of electric vehicles: The mediating role of ethical evaluation. Transp. Res. Part D Transp. Environ. 2017, 56, 175-188. [CrossRef]

43. Simsekoglu, Ö.; Klöckner, C. Factors related to the intention to buy an e-bike: A survey study from Norway. Transp. Res. Part F: Traffic Psychol. Behav. 2019, 60, 573-581. [CrossRef]

44. Barth, M.; Jugert, P.; Fritsche, I. Still underdetected-Social norms and collective efficacy predict the acceptance of electric vehicles in Germany. Transp. Res. Part F Psychol. Behav. 2016, 37, 64-77. [CrossRef]

45. Krause, R.M.; Carley, S.R.; Lane, B.W.; Graham, J.D. Perception and reality: Public knowledge of plug-in electric vehicles in 21 U.S. cities. Energy Policy 2013, 63, 433-440. [CrossRef]

46. Roselius, T. Consumer Rankings of Risk Reduction Methods. J. Mark. 1971, 35, 56-61. [CrossRef]

47. Mitchell, V.W. Consumer perceived risk: Conceptualisations and models. Eur. J. Mark. 1999, 33, $163-195$. [CrossRef]

48. Marriott, H.R.; Williams, M.D. Exploring consumers perceived risk and trust for mobile shopping: A theoretical framework and empirical study. J. Retail. Consum. Serv. 2018, 42, 133-146. [CrossRef] 
49. Chopdar, P.K.; Korfiatis, N.; Sivakumar, V.J.; Lytras, M.D. Mobile shopping apps adoption and perceived risks: A cross-country perspective utilizing the Unified Theory of Acceptance and Use of Technology \&z.star. Comput. Hum. Behav. 2018, 86, 109-128.

50. Menon, N.; Pinjari, A.; Zhang, Y.; Zou, L. Consumer Perception and Intended Adoption of Autonomous-Vehicle Technology: Findings from a University Population Survey. In Proceedings of the Transportation Research Board 95th Annual Meeting, Washington DC, USA, 10-14 January 2016.

51. Zmud, J.; Sener, I.N.; Wagner, J. Consumer Acceptance and Travel Behavior: Impacts of Automated Vehicles; Texas A\&M Transportation Institute: College Station, TX, USA, 2016.

52. Boumiza, S.; Braham, R. Intrusion Threats and Security Solutions for Autonomous Vehicle Networks. In Proceedings of the IEEE/ACS International Conference on Computer Systems \& Applications, Hammamet, Tunisia, 30 October-3 November 2017.

53. Ryerson, M.S.; Miller, J.E.; Winston, F.K. Edge conditions and crash-avoidance roles: The future of traffic safety in the world of autonomous vehicles. Inj. Prev. 2018. [CrossRef] [PubMed]

54. Park, E.; Ohm, J.Y. Factors influencing the public intention to use renewable energy technologies in South Korea: Effects of the Fukushima nuclear accident. Energy Policy 2014, 65, 198-211. [CrossRef]

55. Featherman, M.S.; Pavlou, P.A. Predicting e-services adoption: a perceived risk facets perspective. Int. J. Hum. Comput. Stud. 2003, 59, 451-474. [CrossRef]

56. Ajzen, I.; Cote, N.G. Attitudes and the prediction of behavior. In Frontiers of Social Psychology. Attitudes and Attitude Change; Psychology Press: New York, NY, USA, 2008; pp. 289-311.

57. Liu, D.; Du, H.; Southworth, F.; Ma, S. The influence of social-psychological factors on the intention to choose low-carbon travel modes in Tianjin, China. Transp. Res. Part A Policy Pract. 2017, 105, 42-53. [CrossRef]

58. Stark, J.; Hössinger, R. Attitudes and mode choice: Measurement and evaluation of interrelation. Transp. Res. Procedia 2018, 32, 501-512. [CrossRef]

59. Gao, Y.; Chen, X.; Shan, X.; Fu, Z. Active commuting among junior high school students in a Chinese medium-sized city: Application of the theory of planned behavior. Transp. Res. Part F Traffic Psychol. Behav. 2018, 56, 46-53. [CrossRef]

60. Peng, J.; Jing, W.; Long, C.; Zha, Q. Incorporating the extended theory of planned behavior in a school travel mode choice model: a case study of Shaoxing, China. Transp. Plan. Technol. 2017, 41, 1-19.

61. Wang, S.; Jin, F.; Zhao, D.; Shu, Y.; Fu, Y. Predicting consumers' intention to adopt hybrid electric vehicles: Using an extended version of the theory of planned behavior model. Transportation 2016, 43, 123-143. [CrossRef]

62. Pan, J.Y.; Truong, D. Passengers' intentions to use low-cost carriers: An extended theory of planned behavior model. J. Air Transp. Manag. 2018, 69, 38-48. [CrossRef]

63. Huang, C.C.; Lu, L.C. Examining the Roles of Collectivism, Attitude Toward Business, and Religious Beliefs on Consumer Ethics in China. J. Bus. Ethics 2016, 146, 1-10. [CrossRef]

64. Chen, C.C.; Meindl, J.R.; Hunt, R.G. Testing the effects of vertical and horizontal collectivism: A study of reward allocation preferences in China. Cross Cult. Psychol. 1997, 28, 44-70. [CrossRef]

65. Du, H.; Liu, D.; Sovacool, B.K.; Wang, Y.; Ma, S.; Li, R.Y.M. Who buys New Energy Vehicles in China? Assessing social-psychological predictors of purchasing awareness, intention, and policy. Transp. Res. Part F: Traffic Psychol. Behav. 2018, 58, 56-69. [CrossRef]

66. Howard, D.; Dai, D. Public perceptions of self-driving cars: The case of Berkeley, California. In Proceedings of the Transportation Research Board 93rd Annual Meeting, Washington DC, USA, 12-16 January 2014.

67. Matell, M.S.; Jacoby, J. Is There an Optimal Number of Alternatives for Likert Scale Items? Study I: Reliability and Validity. Educ. Psychol. Meas. 1971, 31, 657-674. [CrossRef]

68. Donald, I.J.; Cooper, S.R.; Conchie, S.M. An extended theory of planned behaviour model of the psychological factors affecting commuters' transport mode use. J. Environ. Psychol. 2014, 40, 39-48. [CrossRef]

69. Lanzini, P.; Khan, S.A. Shedding light on the psychological and behavioral determinants of travel mode choice: A meta-analysis. Transp. Res. Part F Traffic Psychol. Behav. 2017, 48, 13-27.

70. Wang, S.; Wang, J.; Li, J.; Wang, J.; Liang, L. Policy implications for promoting the adoption of electric vehicles: Do consumer's knowledge, perceived risk and financial incentive policy matter? Transp. Res. Part A Policy Pract. 2018, 117, 58-69. [CrossRef]

71. Parkins, J.R.; Rollins, C.; Anders, S.; Comeau, L. Predicting intention to adopt solar technology in Canada: The role of knowledge, public engagement, and visibility. Energy Policy 2018, 114, 114-122. [CrossRef] 
72. Liao, F.; Molin, E.; Timmermans, H.; van Wee, B. Consumer preferences for business models in electric vehicle adoption. Transp. Policy 2019, 73, 12-24. [CrossRef]

73. Hair, J.F.; Sarstedt, M.; Hopkins, L.; G. Kuppelwieser, V. Partial least squares structural equation modeling (PLS-SEM) An emerging tool in business research. Eur. Bus. Rev. 2014, 26, 106-121. [CrossRef]

74. Fornell, C.; Larcker, D.F. Evaluating structural equation models with unobservable variables and measurement error. J. Mark. Res. 1981, 18, 39-50. [CrossRef]

75. Tracey, M.; Vonderembse, M.A.; Lim, J.S. Manufacturing technology and strategy formulation: keys to enhancing competitiveness and improving performance. J. Oper. Manag. 1999, 17, 411-428. [CrossRef]

76. Ajzen, I.; Joyce, N.; Sheikh, S.; Cote, N.G. Knowledge and the Prediction of Behavior: The Role of Information Accuracy in the Theory of Planned Behavior. Basic Appl. Soc. Psychol. 2011, 33, 101-117. [CrossRef]

77. Fishbein, M.; Ajzen, I. Belief, Attitude, Intention and Behavior: An Introduction to Theory and Research; Addison-Wesley Pub. Co.: Boston, MA, USA, 1975.

78. Jai, B.P.S.; Neharika, V.; Sushila, S.; Sinha, R.B.N.; Ushashree, S. Normative predictions of collectivist-individualist intentions and behaviour of Indians. Int. J. Psychol. 2002, October 01, 309-319.

79. Chang, Y.W.; Hsu, P.Y.; Shiau, W.L.; Tsai, C.C. Knowledge sharing intention in the United States and China: A cross-cultural study. Eur. J. Inf. Syst. 2015, 24, 262-277. [CrossRef]

80. İbrahim, A.; Atalar, T. The Exploring Relationships between Environmental Concern, Collectivism and Ecological Purchase Intention. Procedia Soc. Behav. Sci. 2016, 235, 514-521.

81. Katila, R.; Ahuja, G. Something Old, Something New: A Longitudinal Study of Search Behavior and New Product Introduction. Acad. Manag. J. 2002, 45, 1183-1194.

(C) 2019 by the authors. Licensee MDPI, Basel, Switzerland. This article is an open access article distributed under the terms and conditions of the Creative Commons Attribution (CC BY) license (http:/ / creativecommons.org/licenses/by/4.0/). 